\title{
Factors contributing to post-traumatic growth following breast cancer: Results from a randomized longitudinal clinical trial containing psychological interventions
}

\author{
O ZSIGMOND ${ }^{1,2 *}$, A VARGAY $^{1,2}$, E JÓZSA $^{2}$ and É BÁNYAI ${ }^{2}$ \\ ${ }^{1}$ Doctoral School of Psychology, Faculty of Education and Psychology, Eötvös Loránd University, Budapest, Hungary \\ ${ }^{2}$ Institute of Psychology, Faculty of Education and Psychology, Eötvös Loránd University, Budapest, Hungary
}

(Received: February 17, 2019; revised manuscript received: May 30, 2019; accepted: June 12, 2019)

\begin{abstract}
Purpose: The purpose of this study was to explore the factors influencing post-traumatic growth in breast cancer patients during 3 years after diagnosis. Materials and methods: Our longitudinal study involved 71 medium and highrisk breast cancer patients, who received special attention and either hypnosis or music psychological intervention while receiving the same chemotherapy protocol. The influences of the interventions, as well as the demographic (age, marital status, and educational level) and psychosocial factors (coping, post-traumatic stress, and well-being), on post-traumatic growth were explored. Results: The results showed that over $97 \%$ of our patients experienced posttraumatic growth. It was positively associated with Quality of Life domains 3 years after diagnosis, and with Psychological Immune Competence cumulative scores after treatment and 3 years after diagnosis. Psychological Immune Competence, emotional severity of post-traumatic stress symptoms, and the social support scale of Quality of Life explained $33.9 \%$ of the variance of post-traumatic growth. Conclusion: The results confirm that positive coping strategies, emotional severity of post-traumatic stress symptoms, and social support contribute to posttraumatic growth, and that post-traumatic growth has a weak to moderate association with quality of life.
\end{abstract}

Keywords: post-traumatic growth, breast cancer, post-traumatic stress symptoms, coping, social support, interventions

\section{INTRODUCTION}

Breast cancer is the most prevalent form of cancer in women around the world [1] and also the most prevalent form of all tumors in Hungary [2]. The psychosocial effects of breast cancer have high degrees of individual variability, but it is clear that the diagnosis and treatment are particularly distressful [3] and the result in anxiety and even posttraumatic stress disorder (PTSD) [4, 5]. The traumatic nature of cancer has received great attention [4]. Compared to classical traumas, the stressor is more complex and not a one-time event, and it contains a group of traumatic events and considerations associated with the chronic nature of the disease: diagnosis, severity and prognosis of the disease, type of treatment, side effects, body image problems, loss of functionality, and role changes in social life. From the point of coping, it is not just a process of past events, but also the potential for future reintegration of the trauma [6].

Although breast cancer may have many negative psychological consequences, it can also be considered an existential challenge that can result in post-traumatic growth (PTG) [7]. PTG refers to the positive psychological changes and advances that can follow trauma. Through cognitive reintegration processes, relationships, belief systems, attitudes towards life and the future, priorities, and personal power can be reassessed. The cognitive processing of trauma indicates constant, but manageable stress levels $[8,9]$. Traditionally, five fundamental domains of PTG are distinguished [9]: increasing appreciation of life, more meaningful relationships, increased sense of personal strengths, discovering new life possibilities, and spiritual/ existential change.

There are a number of studies on PTG in women during the 5-year period after a diagnosis of breast cancer $[10,11]$. The most significant domains of change are manifested in better appreciation of life and relationships [12, 13]. PTG in breast cancer is influenced by many individual, social, and disease-related factors, such as age [14], social support [15], coping [4], time since diagnosis [10], and cancer-related post-traumatic stress [16], the factors that should be examined in an integrated framework [17]. The results on the degree of influence of each of the factors have been inconsistent. It seems to be a consistent result, however, that the key predictors of PTG are the level of social support and the use of the various coping strategies [18] - which interact

* Corresponding author: Orsolya Zsigmond; Doctoral School of Psychology and Institute of Psychology, Faculty of Education and Psychology, Eötvös Loránd University, Izabella Str. 46, H-1064 Budapest, Hungary; E-mail: alyoosa@gmail.com

This is an open-access article distributed under the terms of the Creative Commons Attribution 4.0 International License, which permits unrestricted use, distribution, and reproduction in any medium, provided the original author and source are credited, a link to the CC License is provided, and changes - if any - are indicated. (SID_1) 
with each other [4]. Tedeschi and Calhoun [9] state that early coping success is prognostic for later PTG. One line of studies also suggests that PTG is related to better quality of life and more optimal functioning in women with breast cancer [7, 19]. Therefore, it may have an adaptive function.

The experience of both positive and negative consequences of breast cancer requires specific consideration from the psychotherapeutic view. Receiving a diagnosis, patients face mortality - their sense of inviolability is suddenly gone - and their entire reference system becomes vulnerable. These, coupled with a lack of information on the disease, can result in a negatively altered state of consciousness (ASC), characterized by relinquishment of control and strengthened emotionality [20]. It is fundamental that, due to the extreme distress caused by the diagnosis and the treatment, many patients seek social support to talk about the stressful event. Besides the comforting effect of social support, it allows for self-discovery in a safe social environment, which can affect the process of restoring the patient's shaken world and deliberate rumination processes [21]. Social support also helps facilitate the coping processes and the finding of meaning in the experience and therefore PTG [7]. Since in the ASC, evoked by the diagnosis of cancer, the patients become more susceptible to suggestions, suggestive techniques like hypnosis or music may be especially effective in mediating social support [20]. The aim of this study was to explore the factors contributing to PTG in a breast cancer sample receiving psychological interventions (hypnosis or music) and special attention. We hypothesized that positive coping after treatment and the level of post-traumatic stress could predict PTG, and that PTG would be positively associated with quality of life.

\section{MATERIALS AND METHODS}

\section{Study framework and participants}

The data presented in this paper were collected during a research project - Psychological Resources and Healing (principal investigator ÉB) - which aimed to analyze the effect of adjuvant hypnosis on survival, quality of life, immune functions, and coping. The prospective, randomized, single-blind, controlled study involved medium and high-risk breast cancer patients, who were diagnosed with histologically confirmed HER2-negative, axillary lymph node-positive, or high-risk, lymph node-negative tumors, without distant metastases and were treated with the same standard chemotherapy protocol $(4 \mathrm{AC}+$ weekly $12 \mathrm{PAC}$ every 3 weeks).

\section{Procedure}

Patients were randomized into two intervention groups (hypnosis $=\mathrm{H}$ or music $=\mathrm{M}$ ), and for ethical considerations, as a control, a third, special-attention (SA) group. This group consisted of patients who were asked to participate in a study that would investigate the relationship between psychological factors and biological parameters, without psychological interventions. The intervention groups received psychological interventions during all chemotherapy sessions and also during blood-count controls. Patients in the $\mathrm{H}$ group listened to a standard hypnotic induction, positive suggestions for strengthening immune functions, and hidden psychological resources. In the $\mathrm{M}$ group, patients listened to a musical composition of the same length and dynamics. All patients were received special attention (extra social support) above standard medical care. During treatment and follow-up, beyond asking the participants about their emotional and physical well-being, psychological questionnaires were registered six times [22, 23].

\section{Measurements}

Demographic variables. As demographic variables, we used the participants' age, education level, and marital status.

Post-Traumatic Growth Inventory (PTGI). PTG was measured by the PTGI [8, 9]. The Hungarian validation of the PTGI provided high reliability (Cronbach's $\alpha=.94$ ) [24]. The PTGI is a 21-item, self-report measure assessing Tedeschi and Calhoun's (see above) five separate domains of PTG on a $0-5$ scale. We used it to assess the degree to which patients had experienced changes in their life after the breast cancer diagnosis. The internal consistency coefficient, Cronbach- $\alpha$, for our measurements was between .809 and .908 for all the domains except Spirituality, which was .612.

WHO Quality of Life-100 (QOL). Quality of Life was measured by WHOQOL-100, a cross-culturally developed, multilingual tool with excellent overall and internal consistency. It measures the satisfaction of a person with physical, psychological, social, and spiritual domains of everyday functioning, in the context of culture and belief systems [25]. The 100 questions cover 24 facets, hierarchically organized within six domains: Physical Health (PHY), Level of Independence (LOI), Psychological (PSY), Social Relations (SOC), Environment (ENV), and Spirituality/Religion/Personal Beliefs (SPI). Cronbach's $\alpha$ for our measurements was between .746-.925 for all the domains except PHY, which was .577.

Psychological Immune Competence Inventory (PICI). Coping capacity was measured by the PICI [26], which is an 80-item inventory containing 16 scales and 3 subordinate systems. The PICI maps the personality resources that enable an individual to withstand and overcome persistent and intense stressful effects. The PICI cumulative score (total score) was used and the internal consistency coefficient, Cronbach's $\alpha$, for our measurements was .899 .

Post-traumatic Stress Diagnostic Scale (PSDS). The PSDS self-report measure was developed by Foa [27] and validated by Foa, Cashman, Jaycox, and Perry [28] using the DSM-IV criteria for PTSD. In the shortened, Hungarian version [29, 30], the patient has to indicate the frequency (FR) and the emotional severity (ES) of the possible posttraumatic stress symptoms (PTSS). The total score indicates the emotional severity of the PTSS. The internal consistency coefficient, Cronbach- $\alpha$, for our measurements was between .922 and .935 .

\section{Data collection and analyses}

We examined the data from psychological questionnaires registered prior to chemotherapy treatment (T1), at the end 
of the treatment $(0.5$ years after diagnosis) (T3), and at the end of the trial (3 years after diagnosis) (T6). The PICI and WHOQOL were registered at T1, T3, and T6. The PTGI and PSDS were registered at T6. The systematization of the data and the execution of statistical procedures were carried out using IBM SPSS Version 23.0 (IBM Corp., Released 2015, Armonk, NY, USA). Descriptive statistical analyses were performed to describe the characteristics of the sample. The differences between the three groups were calculated using one-way ANOVA and, for pairwise comparisons, the Bonferroni post-hoc test was added. For defining effect size, $\omega^{2}$ (omega squared) was used with Cohen's rule of thumb for interpretation of the results. Pearson's correlation method was used to examine the associations between the measured variables and PTG. Linear regression analysis (Enter method) was performed for complex analysis of the variables determining PTG.

\section{RESULTS}

\section{Descriptive statistics}

The sample of this study contained 71 women. The diagnosis, the time since diagnosis, the treatment protocol, and the risk of the diagnosis were controlled, and the sample was homogenous by disease variables. In addition, all participants received continuous special attention from the research team and from each other.
There was no significant difference in age $[F(2,67)=$ $1.637, p=.202)$ or marital status $\left[\chi^{2}(8, N=69)=6.738\right.$, $p=.565)$ among the three groups. The mean age in the $\mathrm{H}$ group was $51.48(S D=12.06)$, in the $\mathrm{M}$ group $55.65(S D=$ $9.81)$, and in the SA group $57.13(S D=10.88)$ years. The majority $(n=46)$ of the patients was married or lived in a relationship $(65.0 \%), 4$ patients $(5.7 \%)$ were single, 8 patients $(11.4 \%)$ were divorced, and 11 patients $(15.7 \%)$ were widowed. The only significant difference in the groups' descriptive characteristics was in educational level $\left[\chi^{2}(4, N=70)=12.748, p=.013\right]$.

\section{Comparison of study variables among the groups}

The descriptive statistics and group differences in the study variables are presented in Table 1. There were no significant differences between the groups in any of the variables.

\section{Characteristics of PTGI}

Patients reported PTG in a moderate to great degree $(M=76.07, S D=21.56$; PTGI total average score: 3.62 , $S D=1.02$ ). Hundred percent of the $\mathrm{H}$ and $\mathrm{SA}$ and $97.2 \%$ of the $\mathrm{M}$ group experienced at least a small degree of change, reported by the average PTGI total score. The highest scores were found for Appreciation of Life, followed by Relationships and Personal Strengths in all groups (Table 2). There were no significant differences between the groups, except in Spiritual Change $[F(2,68)=4,702, p=.012$,

Table 1. Descriptive statistics and group differences in the study variables for the three groups

\begin{tabular}{|c|c|c|c|c|c|c|c|c|c|}
\hline & \multicolumn{2}{|c|}{ Hypnosis } & \multicolumn{2}{|c|}{ Music } & \multicolumn{2}{|c|}{ Special attention } & \multirow[b]{2}{*}{$F$} & \multirow[b]{2}{*}{$p$} & \multirow[b]{2}{*}{$\omega^{2}$} \\
\hline & $M$ & $S D$ & $M$ & $S D$ & $M$ & $S D$ & & & \\
\hline PICI cumulative T1 & 233.96 & 31.71 & 226.00 & 39.19 & 236.64 & 35.43 & 0.468 & .628 & -0.02 \\
\hline PICI cumulative T3 & 244.16 & 29.41 & 231.22 & 39.30 & 239.92 & 39.49 & 0.778 & .464 & -0.01 \\
\hline PICI cumulative T6 & 245.38 & 32.24 & 240.22 & 46.07 & 235.83 & 45.83 & 0.247 & .782 & -0.03 \\
\hline PTSS FR T6 & 10.63 & 8.70 & 8.19 & 11.34 & 11.20 & 9.26 & 0.602 & .550 & -0.01 \\
\hline PTSS ES T6 & 11.83 & 10.67 & 8.04 & 11.94 & 11.27 & 9.14 & 0.919 & .404 & -0.02 \\
\hline QOL SOC T1 & 16.13 & 2.14 & 15.41 & 2.39 & 16.11 & 1.75 & 0.906 & .409 & 0.00 \\
\hline QOL SPI T1 & 14.08 & 3.31 & 14.92 & 3.44 & 15.47 & 2.61 & 0.205 & .815 & -0.02 \\
\hline QOL PHY T1 & 14.75 & 2.41 & 14.51 & 2.59 & 14.06 & 1.98 & 0.412 & .664 & 0.00 \\
\hline QOL PSY T1 & 14.10 & 2.28 & 13.86 & 2.96 & 13.88 & 2.03 & 0.075 & .928 & -0.03 \\
\hline QOL ENV T1 & 15.70 & 1.59 & 15.01 & 1.97 & 15.14 & 1.69 & 1.175 & .315 & 0.00 \\
\hline QOL LOI T1 & 15.49 & 2.78 & 15.21 & 3.32 & 14.06 & 2.03 & 0.485 & .618 & -0.02 \\
\hline QOL SPI T3 & 16.27 & 3.32 & 16.08 & 2.71 & 16.64 & 3.08 & 0.156 & .856 & -0.02 \\
\hline QOL SOC T3 & 15.54 & 2.45 & 14.92 & 2.30 & 16.53 & 2.69 & 1.793 & .175 & 0.02 \\
\hline QOL PHY T3 & 14.40 & 2.59 & 14.26 & 2.67 & 13.83 & 2.34 & 0.239 & .788 & -0.02 \\
\hline QOL PSY T3 & 14.62 & 2.41 & 14.65 & 2.42 & 14.47 & 2.56 & 0.038 & .963 & -0.01 \\
\hline QOL ENV T3 & 15.99 & 1.73 & 15.50 & 1.91 & 15.35 & 2.09 & 0.737 & .482 & -0.01 \\
\hline QOL LOI T3 & 15.70 & 2.55 & 15.07 & 2.85 & 14.82 & 2.50 & 0.666 & .517 & -0.01 \\
\hline QOL SPI T6 & 16.04 & 2.90 & 15.42 & 3.43 & 16.00 & 2.56 & 0.298 & .743 & -0.02 \\
\hline QOL SOC T6 & 15.31 & 2.32 & 14.97 & 2.41 & 14.97 & 2.28 & 0.163 & .850 & -0.03 \\
\hline QOL PHY T6 & 15.08 & 2.06 & 14.26 & 3.82 & 13.28 & 1.43 & 1.841 & .167 & 0.03 \\
\hline QOL PSY T6 & 14.81 & 2.28 & 14.82 & 2.99 & 13.82 & 2.46 & 0.712 & .495 & -0.01 \\
\hline QOL ENV T6 & 16.02 & 1.84 & 15.34 & 2.13 & 15.04 & 2.11 & 1.277 & .286 & 0.01 \\
\hline QOL LOI T6 & 16.44 & 2.25 & 16.23 & 3.11 & 14.46 & 2.31 & 2.561 & .086 & 0.05 \\
\hline
\end{tabular}

Note. SD: standard deviation; PICI: Psychological Immune Competence Inventory; PTSS: post-traumatic stress symptoms; FR: frequency; ES: emotional severity; PHY: physical health; LOI: level of independence; PSY: psychological; SOC: social relations; ENV: environment; SPI: spirituality/religion/personal beliefs. 
Table 2. Group differences in mean PTGI total and factor scores for the three groups

\begin{tabular}{|c|c|c|c|c|c|c|c|c|c|}
\hline & \multicolumn{2}{|c|}{ Hypnosis } & \multicolumn{2}{|c|}{ Music } & \multicolumn{2}{|c|}{ Special attention } & \multirow[b]{2}{*}{$F$} & \multirow[b]{2}{*}{$p$} & \multirow[b]{2}{*}{$\omega^{2}$} \\
\hline & $M$ & $S D$ & $M$ & $S D$ & $M$ & $S D$ & & & \\
\hline PTGI total score & 3.81 & 0.98 & 3.33 & 1.14 & 3.74 & 0.81 & 1.704 & .190 & 0.02 \\
\hline PTGI appreciation of life & 4.3 & 0.85 & 4.02 & 1.16 & 4.42 & 0.77 & 0.956 & .390 & -0.00 \\
\hline PTGI relationships & 3.85 & 1.04 & 3.47 & 1.24 & 3.86 & 0.68 & 1.062 & .352 & 0.00 \\
\hline PTGI personal strengths & 4 & 1.02 & 3.55 & 1.28 & 3.76 & 1.12 & 1.080 & .345 & 0.00 \\
\hline PTGI new possibilities & 3.69 & 1.32 & 3.06 & 1.45 & 3.29 & 1.21 & 1.521 & .226 & 0.01 \\
\hline PTGI spiritual change & 2.85 & 1.64 & 1.98 & 1.44 & 3.36 & 1.12 & 4.702 & .012 & 0.10 \\
\hline
\end{tabular}

Note. For PTGI, average scores are given on the 6-point scale. Above 1 point means small, above 3 points means moderate, and above 4 points means great degree of change experienced. $S D$ : standard deviation; PTGI: Post-traumatic Growth Inventory.

$\left.\left.\omega^{2}=0.10\right)\right]$. In the pairwise comparisons, significantly higher scores were reported in the SA group than in comparison with the $\mathrm{M}$ group. For the $\mathrm{H}$ group, the difference was not significant.

\section{Correlates of PTG and linear regression model for PTG}

Due to small group sizes and minimal group differences, and the fact that the patients all received special attention in addition to medical care during treatment, we merged the groups.

In the bivariate correlations, the QOL PSY, QOL SPI, QOL ENV, and the cumulative PICI at T3 and T6 were moderately significantly and positively correlated with PTG. PTG was in a significant, positive, weak association with QOL PHY, QOL SOC, and QOL LOI at T6, and with cumulative PICI at T1 (Table 3).

Multivariate linear regression analysis was performed for the explanatory variables of the total score of the PTGI. Independent variables (for theoretical reasons) were the cumulative PICI score (T3) and the PTSS ES. The PICI at

Table 3. Bivariate correlation analyses of the variables related to PTG

\begin{tabular}{lc}
\hline & PTGI total score \\
\hline Age at diagnosis & -.010 \\
PTSS ES & -.034 \\
PTSS FR & -.054 \\
QOL SPI T6 & $.433^{* *}$ \\
QOL PHY T6 & $.393^{* *}$ \\
QOL PSY T6 & $.514^{* *}$ \\
QOL ENV T6 & $.476^{* *}$ \\
QOL SOC T6 & $.368^{* *}$ \\
QOL LOI T6 & $.255^{* *}$ \\
PICI cumulative T1 & $.390^{* *}$ \\
PICI cumulative T3 & $.518^{* *}$ \\
PICI cumulative T6 & $.546^{* *}$ \\
\hline
\end{tabular}

Note. Post-traumatic Growth Inventory; PICI: Psychological Immune Competence Inventory; QOL: Quality of Life; PTG: post-traumatic growth; PTSS: post-traumatic stress symptoms; FR: frequency; ES: emotional severity; PHY: physical health; LOI: level of independence; PSY: psychological; SOC: social relations; ENV: environment; SPI: spirituality/religion/personal beliefs. $* * p<.01$.
$\mathrm{T} 3$ was used because between $\mathrm{T} 1$ and $\mathrm{T} 3$ the score increased significantly $[t(58)=-2.389, p=.020, g=0.2]$ (Hedges' $g$ was used to measure effect size), and it was hypothesized that the mobilization of resources - which could affect PTG would be higher after treatment. Furthermore, due to theoretical assumptions, we supposed that the PTSS would have a nourishing effect on PTG. Although we did not measure social support with a separate questionnaire - one scale from QOL measures social support - we used it in the regression model. We used the score from $\mathrm{T} 6$ because we also measured PTG at T6. In the model (see Table 4), the cumulative PICI at T3, the social support scale of QOL at T6, and the PTSS ES were all significant predictors. The model explained $33.9 \%$ of the variance of PTGI $\left[R^{2}=.339\right.$, $\left.R_{\text {adj }}^{2}=.299, F(3,50)=8.547, p<.001\right]$.

\section{DISCUSSION}

The aim of this study was to test the prevalence of PTG, to explore factors contributing to PTG (controlling for demographic and disease variables), and to test the hypothesis of a positive relation between PTG and QOL in a breast cancer sample after receiving psychological interventions and SA during chemotherapy treatment.

According to the PTGI score, more than $97 \%$ of the patients experienced at least a small degree of change, and the total mean score was higher than in other studies including patients with breast cancer $[15,31]$ and psychological interventions [32]. These results can be explained with two inferences: first, in this study, both psychological interventions and special attention were included, which could have increased the rate of PTG [32], and second, the studies suggest that PTG increases over time [10], and we measured PTG 3 years after diagnosis.

There were no significant differences between the intervention groups in their total PTGI scores or in the individual factors of the PTGI, except for the spiritual change difference between the M and SA groups. For the $\mathrm{H}$ and $\mathrm{M}$ groups, the spiritual change detected was small, but in the SA group it was above moderate. First, as far as spirituality is concerned, it is important to point out that there have been no previous studies exploring the relationship between the baseline spirituality/religiousness level of the patients and the spiritual change [33]. For those with a higher initial level, the change could be less visible. 
Table 4. Linear regression model for the predictors of PTGI in the breast cancer sample

\begin{tabular}{|c|c|c|c|c|c|}
\hline & \multicolumn{2}{|c|}{ Unstandardized coefficients } & \multirow{2}{*}{$\frac{\text { Standardized coefficients }}{\beta}$} & \multirow[b]{2}{*}{$t$} & \multirow[b]{2}{*}{$p$} \\
\hline & $B$ & Standard error & & & \\
\hline PICI cumulative T3 & 0.299 & 0.088 & 0.520 & 3.398 & .001 \\
\hline PTSS ES & 0.641 & 0.285 & 0.355 & 2.252 & .029 \\
\hline QOL Social Support Scale T6 & 2.599 & 1.197 & 0.333 & 2.171 & .035 \\
\hline
\end{tabular}

Note. Post-Traumatic Growth Inventory; PICI: Psychological Immune Competence Inventory; PTSS: post-traumatic stress symptoms; QOL: Quality of Life; ES: emotional severity.

Second, it is also important to emphasize that the Spirituality Scale contains very few items, and its reliability is below that of the other scales. Third, since spirituality might be culturally affected, Tedeschi, Cann, Taku, SenolDurak, and Calhoun [34] have suggested a revision and expansion of the PTGI.

Consistent with previous findings [4, 35], among the domains of the PTGI, the highest scores were found for Appreciation of Life, followed by Relationships and Personal Strengths in all groups and also when combined. It must also be acknowledged that the scores on the New Possibilities Scale were also above moderate. Further research is needed for a deeper understanding of the dimensions of PTG in a breast cancer sample. It would also aid in the design of target-oriented interventions and clinical work [36].

There were also no significant differences between the groups regarding the PICI scales and QOL domains at T1, T3, and T6, and PSDS scales at T6. The result at T1 can be the result of one or both of two factors: the groups were quite homogenous and the group size was relatively small. For T3 and T6, the explanation could be more complex than at the baseline, because the treatment and the interventions also must have had an effect. First, although the patients were receiving the same treatment protocol, we did not measure the perceived stress of the treatment. It could have been individually different. Second, the received special attention from the research team and from the other patients could have been more effective than the interventions. The support experienced among our patients towards each other could have had a significant effect, which we did not predict early on and therefore did not measure. According to the theoretical and also to the research literature, social support during diagnosis and treatment is one of the key factors for mobilizing inner resources and even PTG in the long run [37, 38].

We hypothesized that the positive coping strategies measured after treatment (T3) could predict PTG 3 years after diagnosis. The results showed that the PICI scores increased significantly between $\mathrm{T} 1$ and $\mathrm{T} 3$. This could have occurred due to the mobilization of inner resources by the psychological interventions and special attention. The results showed that the cumulative PICI score at T3, together with the PTSS ES and the social support scale of QOL at T6, explained $33.9 \%$ of the PTGI variance. Consistent with previous findings, PTSS co-occurs with PTG [4], and the presence of distress is necessary to develop PTG [9]. Also, the co-occurrence of PTG and PTSS raises questions about the adaptive function of PTG [31]. How could PTG be adaptive, if the emergence of PTG is accompanied by PTSS? First, consistent with previous findings, the constant cognitive involvement in processing the trauma - which requires stress - could be a key factor in the development of PTG [9]. On the other hand, results of the current study showed that PTGI and QOL domains have moderate to strong associations. These results could confirm the theory of the adaptive function of PTG, but also raises many other questions. Does PTG lead to better well-being [19]? Reciprocal relationships can also be cited, as in a state of stable well-being, people may be more inclined to see more positive changes that are reflected in their well-being notion.

\section{Limitations}

The results should be interpreted with caution, as the variables examined were measured by self-report questionnaires, and the sample size was relatively small. Small sample size in a clinical study with cancer patients is a general problem. Participation was voluntary, so the sample was biased. The perceived severity of the diagnosis and treatment, which would provide useful information on the extent of the threat, might have been profitably assessed. The question also arises as to whether each person in the study considered the disease as a trauma.

Not measuring social support with a separate questionnaire was also a limitation of this study. For future considerations, it would be useful to measure PTG (and PTG dimensions separately) and PTSS longitudinally, during and after treatment, to examine reintegration of the trauma.

\section{CONCLUSIONS}

Despite the limitations, our research provides useful information for planning future interventions. PTG was higher in this study than in other breast cancer samples examined, even if intervention was used. It is clear from the results that it is worthwhile helping people who have undergone breast cancer, not only individually, but also with psychological interventions that use and facilitate social support and suggestive techniques. This study confirms the idea that positive coping strategies and the severity of PTSS contribute to PTG. It further shows that PTG has a weak to moderate association with Quality of Life. Facilitating PTG could therefore be a cost-effective tool to help breast cancer patients. 
Authors' contribution: OZs and ÉB summarized the theoretical background of the paper. OZs, AV, EJ, and ÉB collected the data. OZs executed the statistical analysis. $\mathrm{OZs}, \mathrm{AV}$, ÉB, and EJ summarized, concluded and finalized the text.

Ethical approval: Psychological Resources and Healing Research was conducted with the permission of the Hungarian Medical Research Council Research Ethics Committee (ETT-TUKEB) [39447 - /2013/EKU (465/ 2013)] and 15530-0/2010-1018EKU (670/PI/10).

Conflicts of Interest/Funding: The authors declare no conflict of interest. This study was a part of the "Psychological Resources and Healing" research, which is supported by the Hungarian Scientific Research Fund OTKA/NKFI K109187.

\section{REFERENCES}

1. Ferlay JD, Parkin M, Steliarova-Foucher E. Estimates of cancer incidence and mortality in Europe in 2008. Eur J Cancer. 2010;46(4):765-81.

2. Juhos É. A legjellemzőbb daganatos betegségek onkopszichológiai sajátosságai. Emlörák. [Psycho-oncological specialities of the most common cancer diseases. Breast cancer]. In: Horti J, Riskó Á, eds. Onkopszichológia a gyakorlatban [Psycho-oncology in Practice]. Budapest: Medicina; 2006. p. $134-39$.

3. Helms RL, O'Hea EL, Corso M. Body image issues in women with breast cancer. Psychol Health Med. 2008;13(3):313-25.

4. Cordova MJ, Giese-Davis J, Golant M, Kronenwetter C, Chang V, Spiegel D. Breast cancer as trauma: posttraumatic stress and posttraumatic growth. J Clin Psychol Med Setting. 2007;14(4):308-19.

5. Fors EA, Bertheussen GF, Thune I, et al. Psychosocial interventions as part of breast cancer rehabilitation programs? Results from a systematic review. Psychooncology. 2011;20(9):909-18.

6. Sumalla EC, Ochoa C, Blanco I. Posttraumatic growth in cancer: reality or illusion? Clin Psychol Rev. 2009;29(1):24-33.

7. Brix SA, Bidstrup PE, Christensen J, et al. Post-traumatic growth among elderly women with breast cancer compared to breast cancer-free women. Acta Oncol. 2013;52:345-54.

8. Tedeschi RG, Calhoun LG. The Posttraumatic Growth Inventory: measuring the positive legacy of trauma. J Trauma Stress. 1996;9:455-71.

9. Tedeschi RG, Calhoun LG. Posttraumatic growth: conceptual foundations and empirical evidence. Psychol Inq. 2004;15:1-18.

10. Danhauer SC, Case LD, Tedeschi R. Predictors of posttraumatic growth in women with breast cancer: posttraumatic growth and breast cancer. Psychooncology. 2013;22(12): 2676-83.

11. Coroiu A, Körner A, Burke S, Meterissian S, Sabiston CM. Stress and posttraumatic growth among survivors of breast cancer: a test of curvilinear effects. Int J Stress Manag. 2016;23(1):84-97.
12. Svetina M, Nastran K. Family relationships and post-traumatic growth in breast cancer patients. Psychiatr Danub. 2012;24(3): 298-306.

13. Manne S, Ostroff J, Winkel G, Goldstein L, Fox K, Grana G. Posttraumatic growth after breast cancer: patient, partner, and couple perspectives. Psychosom Med. 2004;66:442-54.

14. Boyle CC, Stanton AL, Ganz PA, Bower JE. Posttraumatic growth in breast cancer survivors: does age matter? PsychoOncology. 2017;26(6):800-7.

15. Lelorain S, Tessier P, Florin A, Bonnaud-Antignac A. Posttraumatic growth in long term breast cancer survivors: relation to coping, social support and cognitive processing. J Health Psychol. 2012;17:627-39.

16. Koutrouli N, Anagnostopoulos F, Potamianos G. Posttraumatic stress disorder and posttraumatic growth in breast cancer patients: a systematic review. Women Health. 2012;52: 503-16.

17. Zsigmond O, Rigó A, Bányai É. A daganatos betegségek Janus arca: a poszttraumás növekedés jelensége. [The Janus faces of cancer: the phenomenon of posttraumatic growth]. Mentálhigiéné és Pszichoszomatika. [Journal of Mental Health and Psychosomatics]. 2017;18(2):149-70.

18. Bussell VA, Naus MJ. A longitudinal investigation of coping and posttraumatic growth in breast cancer survivors. J Psychosoc Oncol. 2010;28:61-78.

19. Sawyer A, Ayers S, Field AP. Posttraumatic growth and adjustment among individuals with cancer or HIV/AIDS: a meta-analysis. Clin Psych Rev. 2010;30(4):436-47.

20. Bányai É. Hipnózis a pszichoonkológiában [Hypnosis in psychooncology]. In: Vértes G, ed. Hipnózis-Hipnoterápia [HypnosisHypnotherapy]. Budapest: Medicina; 2015. p. 241-67.

21. Ramos C, Leal I, Tedeschi RG. Protocol for the psychotherapeutic group intervention for facilitating posttraumatic growth in nonmetastatic breast cancer patients. BMC Womens Health. 2016;16(1):22.

22. Bányai É. "Psychological resources and healing" (The effect of adjuvant hypnotherapy on survival, immune functions and quality of life of intermediate and high-risk breast cancer patients). OTKA K109187 grant, Hungarian Scientific Research Fund, Budapest, 2013.

23. Bányai É, Józsa E, Jakubovits E, Vargay A, Zsigmond O, Horváth Zs. Evidence based research on the role of hypnosis as a psychological intervention in the care of breast cancer patients: a randomized prospective controlled study. Paper presented at 2017 World Congress of Psycho-Oncology, Berlin, Germany; 2017, August 14-18.

24. Kovács É, Balog P, Preisz L. A Poszttraumás Növekedésérzés Kérdőív pszichometriai mutatói hazai mintán [Psychometric characteristics of the Posttraumatic Growth Inventory in a Hungarian sample]. Mentálhigiéné és Pszichoszomatika [Journal of Mental Health and Psychosomatics]. 2012;13(1):57-84.

25. The WHOQOL Group. The World Health Organization Quality of Life Assessment (WHOQOL): development and general psychometric properties. Soc Sci Med. 1998;46(12): 1569-85.

26. Oláh A. Érzelmek, megküzdés és optimális élmény [Emotions, coping, optimal experience]. Budapest: Trefort Press; 2005.

27. Foa E. Posttraumatic Diagnostic Scale Manual. Minneapolis, MN: National Computer Systems; 1996. 
28. Foa E, Cashman L, Jaycox L, Perry K. The validation of a selfreport measure of PTSD: the Posttraumatic Diagnostic Scale. Psychol Assess. 1997;9(4):445-51.

29. Perczel Forintos D, Ajtay Gy, Barna Cs, Kiss Zs, Komlósi S. Kérdőívek, becslőskálák a klinikai pszichológiában [Questionnaires, scales in clinical psychology]. Budapest: Semmelweis Kiadó; 2012.

30. Perczel Forintos D. Hiedelmek és tévhiedelmek. Bizonyítékokon alapuló módszerek a klinikai pszichológiában. (Habilitációs dolgozat) [Beliefs and misplaced beliefs. Evidence based methods in clinical psychology (Habilitation thesis)]. Budapest, Hungary: Semmelweis University, 2002. (in Hungarian)

31. Pat-Horenczyk R, Perry S, Hamama-Raz Y, Ziv Y, SchrammYavin S, Stemmer SM. Posttraumatic growth in breast cancer survivors: constructive and illusory aspects. J Traumatic Stress. 2015;28(3):214-22.

32. Garland SN, Carlson LE, Cook S, Lansdell L, Speca M. A non-randomized comparison of mindfulness-based stress reduction and healing arts programs for facilitating posttraumatic growth and spirituality in cancer outpatients. Support Care Cancer. 2007;15(8):949-61.
33. Shaw A, Joseph S, Linley PA. Religion, spirituality, and posttraumatic growth: a systematic review. Ment Health Relig Cult. $2005 ; 8(1): 1-11$.

34. Tedeschi RG, Cann A, Taku K, Senol-DurakE, Calhoun LG. The Posttraumatic Growth Inventory: a revision integrating existential and spiritual change. J Trauma Stress. 2017;30(1):11-8.

35. Mols F, Vingerhoets AJ, Coebergh JWW, Van de Poll-Franse LV. Well-being, posttraumatic growth and benefit finding in long-term breast cancer survivors. Psychol Health. 2009;24(5):583-95.

36. Stefanic N, Caputi P, Lane L, Iverson DC. Exploring the nature of situational goal-based coping in early-stage breast cancer patients: a contextual approach. Eur J Oncol Nurs. 2015;19(6):604-11.

37. Tedeschi RG, Calhoun LG. Expert companions: posttraumatic growth in clinical practice. In: Calhoun LG, Tedeschi RG, eds. Handbook of Posttraumatic Growth: Research and Practice. New York: Psychology Press; 2006. p. 291-310.

38. Scrignaro M, Barni S, Magrin ME. The combined contribution of social support and coping strategies in predicting posttraumatic growth: a longitudinal study on cancer patients. Psychooncology. 2011;20(8):823-31. 